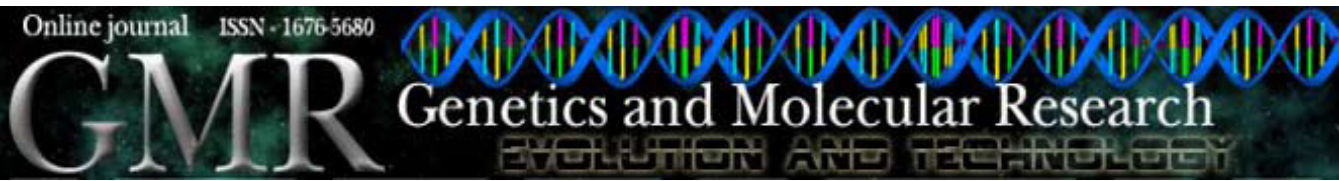

\title{
Agronomic characterization, genetic diversity and association analysis of cotton cultivars using simple sequence repeat molecular markers
}

\author{
A. Kalivas ${ }^{1}$, F. Xanthopoulos ${ }^{2}$, O. Kehagia ${ }^{2}$ and A.S. Tsaftaris ${ }^{1,3}$ \\ ${ }^{1}$ Institute of Agrobiotechnology, Centre for Research and Technology Hellas, \\ Thermi, Greece \\ ${ }^{2}$ Cotton and Industrial Plants Institute, National Agricultural Research Foundation, \\ Sindos, Greece \\ ${ }^{3}$ Department of Genetics and Plant Breeding, Aristotle University of Thessaloniki, \\ Thessaloniki, Greece
}

Corresponding author: A.S. Tsaftaris

E-mail: tsaft@certh.gr

Genet. Mol. Res. 10 (1): 208-217 (2011)

Received October 10, 2010

Accepted December 2, 2010

Published February 8, 2011

DOI 10.4238/vol10-1gmr998

\begin{abstract}
Cotton is the most important textile plant in the world and is one of the most important crops for the production of oilseed. Because of its worldwide economic importance, new cultivars are constantly being released in the world and consequently in the Greek market, as Greece is the largest producer in Europe. We used simple sequence repeat (SSR) markers for the identification and the phylogenetic analysis of the most widely cultivated cotton cultivars in Greece. Initially, we used 12 pairs of SSR molecular markers for the analysis of 29 cultivars of Gossypium hirsutum and an interspecific hybrid (G. hirsutum x G. barbadense). Of the 12 pairs of SSR primers, 11 amplified polymorphic products, while one pair did not amplify any product. Globally, 17 polymorphic marker loci were identified. Two to four different alleles were amplified at each genomic locus, with a mean of 2.53 alleles per locus. Among the 30 genotypes that we analyzed,
\end{abstract}


the polymorphism information content ranged from 0 to 0.548 , with a mean of 0.293 . Three main groups were formed among the 30 genotypes when a phylogenetic analysis was performed using UPGMA. Computational analysis of each molecular marker separately showed an association of SSR markers with agronomic traits such as fiber quality. To our knowledge, this is the first in-depth molecular analysis of cotton cultivars grown in Greece using SSR markers. An analysis of association of SSR markers with fiber quality traits of 29 cotton cultivars is reported for the first time.

Key words: Gossypium hirsutum; SSR; Association; Fiber

\section{INTRODUCTION}

Cotton (Gossypium spp) is one of the most intensively cultivated species worldwide in more than 80 countries and in varying climatic conditions. Cotton constitutes the most important textile plant in the world and is one of the most important crops for the production of oilseed (Zhang et al., 2007). Because of its worldwide economic importance, new cultivars are constantly being released in the world and consequently in the Greek market, where Greece is the largest producing country in Europe. The large number of improved cultivars in combination with their narrow genetic base and economic importance of seed production have increased the need for reliable and effective methods for the identification and certification of these cultivars, as well as germplasm classification for crosses. Until recently, morphological and biochemical markers were used for the identification of new cultivars, but they are influenced by the environment. Among the different types of polymerase chain reaction (PCR)-based DNA markers that have been used in cotton genome research, the most widely used has been random amplified polymorphic DNA (RAPD) (Multani and Lyon, 1995; Tatineni et al., 1996; Iqbal et al., 1997; Lu and Myers, 2002). Allozymes (Wendel et al., 1992), restriction fragment length polymorphism (RFLP) (Rong et al., 2004), and amplified fragment length polymorphism (AFLP) (Abdalla et al., 2001) have also been successfully used in genetic diversity analyses in many species, including cotton. However, the level of polymorphism detectable is low, with allozymes and RFLP markers having low intra- and interspecific polymorphism. These types of markers show low efficiency when applied to the genotyping of large genomes such as the polyploid cotton genome (Liu et al., 2000a). Today, simple sequence repeats (SSR) or microsatellites are considered to be the most important molecular markers, which have been used in various studies (Nguyen et al., 2004; Park et al., 2005; Frelichowski Jr. et al., 2006; Han et al., 2006). SSR markers have been successfully used in many genetic diversity studies (Liu et al., 2000b; Gutierrez et al., 2002) and are useful for a cultivar for applications in plant genetics and breeding because of their large specification for the amplified genomic loci, their high degree of polymorphism (Saghai Maroof et al., 1994), their codominant nature (Akkaya et al., 1995) and their distribution in the whole genome (Hakki et al., 2001). The availability and abundance of SSR markers throughout the cotton genome coupled with the fact that they are polymorphic, codominant and are based on PCR make them particularly useful in genetic diversity studies of cotton (Zhang et al., 2008). Furthermore, more than 1000 SSR primers have already been designed from existing cotton DNA sequences in genomic libraries (Nguyen et al., 2004). 
Herein, we report our studies of genetic diversity using SSR molecular markers and the phylogenetic agronomic relationships among the elite cotton cultivars cultivated in several regions of Greece. Moreover, an analysis of the association of SSR markers with fiber quality traits of cotton cultivars is reported.

\section{MATERIAL AND METHODS}

We investigated 29 Gossypium hirsutum L. and one interspecific hybrid (G. hirsutum L. x G. barbadense L.) cotton cultivars of different origin, including some that were bred and developed locally, which are cultivated in Greece (Table 1). For each cultivar, we extracted total DNA from 10 different plants using a method based on that described by Li et al. (2001). The quality of DNA was evaluated by spectrophotometry using the $260 / 280 \mathrm{~nm}$ absorbance ratio method and by electrophoreses on a $1 \%(\mathrm{w} / \mathrm{v})$ agarose gel, and the DNA concentration estimated at $260 \mathrm{~nm}$ (Sambrook et al., 1989). The stock DNA samples were stored at $-20^{\circ} \mathrm{C}$ and working DNA samples (containing $50 \mathrm{ng} / \mu \mathrm{L}$ ) at $4^{\circ} \mathrm{C}$.

\begin{tabular}{|c|c|c|c|c|c|}
\hline Cultivar & Lint yield (t/ha) & Lint percentage $(\%)$ & Fiber length $(\mathrm{mm})$ & Micronaire & Fiber strength (g/tex) \\
\hline 1. ARIA & 1.04 & 39.4 & 30.0 & 4.4 & 29.8 \\
\hline 2. SADRA & 1.33 & 38.9 & 28.9 & 4.7 & 24.8 \\
\hline 3. S. GROWN & 1.20 & 40.1 & 29.6 & 4.7 & 26.6 \\
\hline 4. BRAVO & 1.47 & 41.3 & 27.9 & 4.7 & 23.7 \\
\hline 5. CELIA & 1.26 & 41.8 & 30.2 & 4.4 & 31.4 \\
\hline 6. VERED & 0.99 & 37.5 & 30.9 & 4.4 & 29.7 \\
\hline 7. BOLINA & 1.44 & 38.3 & 29.2 & 4.4 & 23.6 \\
\hline 8. CONDOR & 1.20 & 40.2 & 28.9 & 4.7 & 24.3 \\
\hline 9. ACSJ2 & 1.09 & 38.1 & 29.8 & 4.7 & 29.8 \\
\hline 10. ZETA-2 & 1.09 & 38.4 & 30.0 & 4.7 & 29.9 \\
\hline 11. ETHIAGE-1 & 1.49 & 40.6 & 30.1 & 4.0 & 26.3 \\
\hline 12. DRIMA & 1.05 & 38.3 & 29.1 & 4.7 & 28.1 \\
\hline 13. EVA & 1.11 & 35.6 & 29.6 & 4.0 & 26.9 \\
\hline 14. VELOS & 1.15 & 39.9 & 29.6 & 4.7 & 26.6 \\
\hline 15. MIDAS & 1.35 & 42.8 & 28.7 & 4.7 & 25.5 \\
\hline 16. ALEGRIA & 1.20 & 40.7 & 29.5 & 4.4 & 26.4 \\
\hline 17. PONTOS & 1.15 & 40.6 & 30.7 & 4.7 & 27.9 \\
\hline 18. ELINA & 1.17 & 39.1 & 28.7 & 4.4 & 25.3 \\
\hline 19. ZOI & 1.14 & 38.8 & 29.3 & 4.7 & 26.9 \\
\hline 20. ETNA & 1.09 & 38.3 & 34.5 & 4.0 & 30.1 \\
\hline 21. D. OPAL & 1.23 & 39.8 & 30.0 & 4.4 & 29.9 \\
\hline 22. CORONA & 1.42 & 38.8 & 28.8 & 4.4 & 24 \\
\hline 23. CARMEN & 1.32 & 41.1 & 30.3 & 4.4 & 28.8 \\
\hline 24. VOLKANO & 1.18 & 37.8 & 29.4 & 4.7 & 25.4 \\
\hline 25. NOVA & 1.16 & 39.1 & 30.5 & 4.7 & 29.3 \\
\hline 26. HERMES & 1.49 & 39.7 & 29.1 & 4.7 & 26 \\
\hline 27. CHRISTINA & 1.19 & 35.9 & 29.8 & 4.0 & 25.9 \\
\hline 28. ACALA & 1.09 & 38.4 & 30.0 & 4.7 & 29.9 \\
\hline \multicolumn{6}{|l|}{ 29. LA5 } \\
\hline 30. McNAIR & 1.14 & 38.8 & 28.9 & 4.4 & 29.8 \\
\hline
\end{tabular}

When cotton was mature, 50 sound, open bolls were hand harvested from each plot for measuring yield, lint percentage and fiber quality. The bolls were ginned in an experimental roller gin (Platt Ginning Equipment Ltd.), and fiber quality traits including length, strength and micronaire were evaluated. Length was measured using a Fibrograph 530 (Spinlab, USA), according to ASTM standards D-1447-89, strength was measured using a Pressley F215 Tester 
(SDL International) according to ASTM standards D-1445-95, and micronaire was measured with Fibronaire (Motion Control Inc., USA), according to ASTM standards D-1148-90.

We used 12 primer pairs to investigate genetic variation and phylogeny in our 30 cotton cultivars. Eleven of 12 primer pairs easily produced detectable products. Amplifications were carried out in $200-\mu \mathrm{L}$ microtubes containing a $50 \mu \mathrm{L}$ reaction mix consisting of 50 ng template, $0.2 \mu \mathrm{M}$ of each primer, $1 \mathrm{U}$ Taq DNA polymerase (Finzymes), $0.2 \mathrm{mM}$ of each dNTP, 0.2 to $0.325 \mathrm{mM} \mathrm{MgCl}_{2}$ (Table 2), and $1 \mathrm{X}$ reaction buffer $(10 \mathrm{mM}$ Tris- $\mathrm{HCl}$ and 50 $\mathrm{mM} \mathrm{KCl}, \mathrm{pH} 8.3$ ). The amplification was carried out in a UNOII thermocycler (BIOMETRA) using a program consisting of a denaturation step of $3 \mathrm{~min}$ at $94^{\circ} \mathrm{C}$ followed by 40 cycles of $40 \mathrm{~s}$ at $94^{\circ} \mathrm{C}, 40 \mathrm{~s}$ at $55^{\circ} \mathrm{C}$, and $1 \mathrm{~min}$ at $72^{\circ} \mathrm{C}$. The program ended with an extension step at $72^{\circ} \mathrm{C}$ for $10 \mathrm{~min}$. The amplified fragments were electrophoretically separated using a $4 \%(\mathrm{w} / \mathrm{v})$ Metaphor agarose gel (Cambrex Bio Science Rockland, Inc.). A 20-bp DNA ladder (Cambrex) was loaded on each gel as a fragment length standard. The gels were stained for 30 min using ethidium bromide $(1 \mu \mathrm{g} / \mathrm{mL})$ and photographed under ultraviolet light (UVItec Limited, Cambridge, UK). Fragment length was determined using the UVIDocMw software (UVItec). Most SSR primers usually amplified 1 or 2 major bands. For the SSR markers, all the alleles were treated independently as a binary variable with 1 for presence and 0 for absence, because heterozygous status for codominant markers in the true breeding cultivars or lines was very rare, if any.

The genetic diversity of each SSR locus was obtained by calculating the frequency of the SSR allele based on polymorphism information content (PIC) using the equation:

$$
\mathrm{PIC}=1-j=1-\sum_{j=1}^{n} p_{i j}^{2}
$$

where $p_{i j}$ is the frequency of the $j t h$ allele for primer $i$ (Anderson et al., 1993).

Genetic similarity coefficients were calculated based on Jaccard's coefficient (JC) using the Numerical Taxonomy Multivariate Analysis System (NTSYSpc), Version 2.1, software package (Rohlf, 2000). The resulting similarity coefficients were used to perform the cluster analysis using the unweighted pair group method with arithmetic mean (UPGMA).

The correlation significance level between molecular markers and agronomic traits of cotton fiber was evaluated using the SPSS 15.0 (version 15.0, SPSS Inc., Chicago, USA) statistical program. With the same software, we calculated Pearson's biserial correlation coefficient, while the $\mathrm{P}$ value for presence and absence of each molecular marker was estimated with the Mann-Whitney non-parametric test using the Monte-Carlo method.

\section{RESULTS AND DISCUSSION}

The 12 pairs of BNL SSR primers amplified 17 polymorphic loci among 30 commercial cotton cultivars, which are cultivated in Greece. The major SSR bands amplified were in agreement with previously published results with other cotton genetic material (Liu et al., 2000b). Genetic similarities based on JC among the 30 genotypes ranged from 0.139 to 1 , with an average of 0.525 . This was low compared to previously published results (Liu et al., 2000b; Gutierrez et al., 2002). In our study, we chose informative SSR markers (BNL SSR markers) that produced higher polymorphism within upland cotton based on other studies (Liu 
et al., 2000a,b). Thus, the genetic similarity obtained is not as high as in these studies that used randomly chosen markers, which may provide more accurate estimates of genetic similarities if they are evenly distributed across the cotton genome. Moreover, we used only polymorphic markers in the estimation of genetic similarity. The coefficient similarity between 5 pairs (EVA-ETHIAGE-1, MIDAS-VELOS, S. GROWN-BRAVO, ZETA-2-DRIMA, and SADRAVOLCANO) of cultivars is 1 , which suggests that these cultivars are very closely related concerning their genetic background or they have a common ancestor. The lowest similarity (0.139) was estimated between hybrid ETNA and cultivars S. GROWN and BRAVO. This was expected since ETNA is an interspecific hybrid between $G$. hirsutum and G. barbadense.

The 11 pairs of SSR primers amplified a total of 44 alleles with an average of 2.53 per SSR locus and PIC values varying from 0.032 to 0.548 with an average of 0.293 (Table 2). This is in agreement with results reported by Liu et al. (2000b), who found that the average PIC value for all 62 SSR marker loci was 0.31 , with a range from 0.05 to 0.82 . Our PIC values were somewhat lower than those found by Liu et al. (2000b), which could be due to the fact that the cultivars used in our study came from breeding programs and could therefore have a narrow genetic base. On the contrary, Liu et al. (2000b) used 97 wild G. hirsutum accessions, which may explain the higher polymorphism ( 5 alleles per locus found). Gutierrez et al. (2002) found an average of 2 alleles per SSR locus, but a large number of the cotton cultivars used came from breeding programs in the United States and Australia, which are known to have a narrow genetic base (Multani and Lyon, 1995; Iqbal et al., 1997; Gutierrez et al., 2002). Similar results were obtained by Bertini et al. (2006) using 53 cotton cultivars that came from breeding programs and, therefore, had a narrow genetic base. In this study, Bertini et al. (2006) found an average of 2.13 alleles per SSR locus and PIC values varying from 0.18 to 0.62 .

$\begin{aligned} & \text { Table 2. The results of statistical analysis using the PowerMarker V3.0 computational program for } 12 \text { SSR } \\
& \text { molecular markers. }\end{aligned}$
\begin{tabular}{lccc}
\hline Molecular marker & Frequency of major allele & Number of alleles & PIC \\
\hline BNL3649 & 0.800 & 2 & 0.269 \\
CM43A & 0.833 & 2 & 0.234 \\
CM43B & 0.900 & 2 & 0.164 \\
BNL3627 & 0.567 & 2 & 0.371 \\
BNL1414 & 0.983 & 2 & 0.032 \\
BNL1317A & 0.500 & 3 & 0.548 \\
BNL1317B & 0.700 & 3 & 0.398 \\
BNL840 & 0.767 & 2 & 0.360 \\
BNL1440A & 0.700 & 2 & 0.332 \\
BNL1440B & 0.533 & 2 & 0.374 \\
BNL3408A & 0.733 & 3 & 0.315 \\
BNL3408B & 0.900 & 2 & 0.175 \\
BNL2634A & 0.533 & 3 & 0.456 \\
BNL2634B & 0.933 & 3 & 0.117 \\
BNL3590A & 0.633 & 3 & 0.396 \\
BNL3590B & 0.633 & 1 & 0.396 \\
BNL686A & 0.950 & 2.53 & 0.094 \\
BNL686B & 1 & & 0.000 \\
Mean & 0.743 & & 0.293 \\
\hline PIC = p0lym
\end{tabular}

$\mathrm{PIC}=$ polymorphism information content.

Nevertheless, higher PIC values have been reported in cotton (Park et al., 2005; Frelichowski Jr. et al., 2006). Lower PIC values may be attributed to the Metaphor agarose, which we used in the analysis of cotton cultivars, contrary to previous studies in which sequencers 
had been used. Most molecular markers that were used produced products of $150-250 \mathrm{bp}$. Using Metaphor agarose it is not possible to separate 2 alleles that differ by one repeat ( 2 bases) as the resolution is limited to small DNA fragments that differ in size by more than $2 \%$.

Molecular marker BNL1414 was proved to be the least informative marker with a PIC of 0.032, while, on the contrary, BNL1317A was proved to be the most informative with a PIC of 0.548. Markers with higher PIC values have the potential to reveal the variation between alleles and could be used more effectively for molecular mapping and analysis of genetic variation in a population (Andersen and Lubberstedt, 2003).

The 11 polymorphic molecular markers amplified from 1-4 alleles for each locus with BNL1317B found to amplify 4 alleles. In a similar study in cotton (Liu et al., 2000b) the BNL1317B molecular marker amplified 4 alleles. This marker is an informative marker with a PIC of 0.398, while a similar PIC has been reported by Liu et al. (2000b).

An SSR profile was constructed for each cultivar using the 11 primer pairs, which were able to discriminate between 20 of the 30 cultivars studied $(66 \%)$. The 10 cultivars that could not be separated were EVA-ETHIAGE-1, MIDAS-VELOS, S. GROWN-BRAVO, ZETA-2-DRIMA, and SADRA-VOLCANO (Figure 1). This suggests that these cultivars are very closely related concerning their genetic background or they have a common ancestor. This profile produced by the 11 SSR markers can be used for identification and seed certification of each cultivar. The profile of each cultivar can help the seed industries towards the certification and the protection of rights of cotton cultivars.

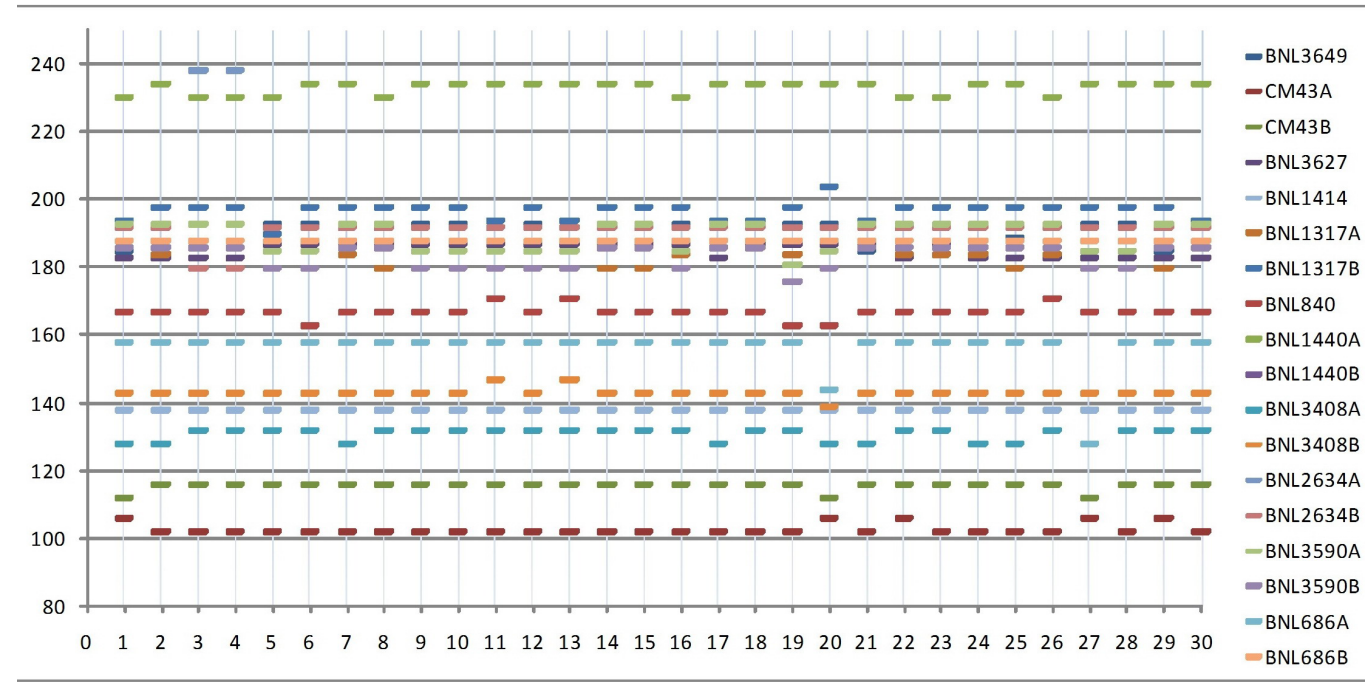

Figure 1. Profile of amplified products for the analysis of 30 cotton cultivars, using 11 SSR molecular markers. Each number of horizontal axes corresponds to the 30 cultivars listed in Table 1. Numbers in the vertical axes indicate the size of the amplified DNA (in bp).

Phylogenetic analysis revealed that the 30 cotton cultivars that were examined belong to 3 main groups (Figure 2). The third group is constituted by cultivars that have a common ACALA ancestor. 


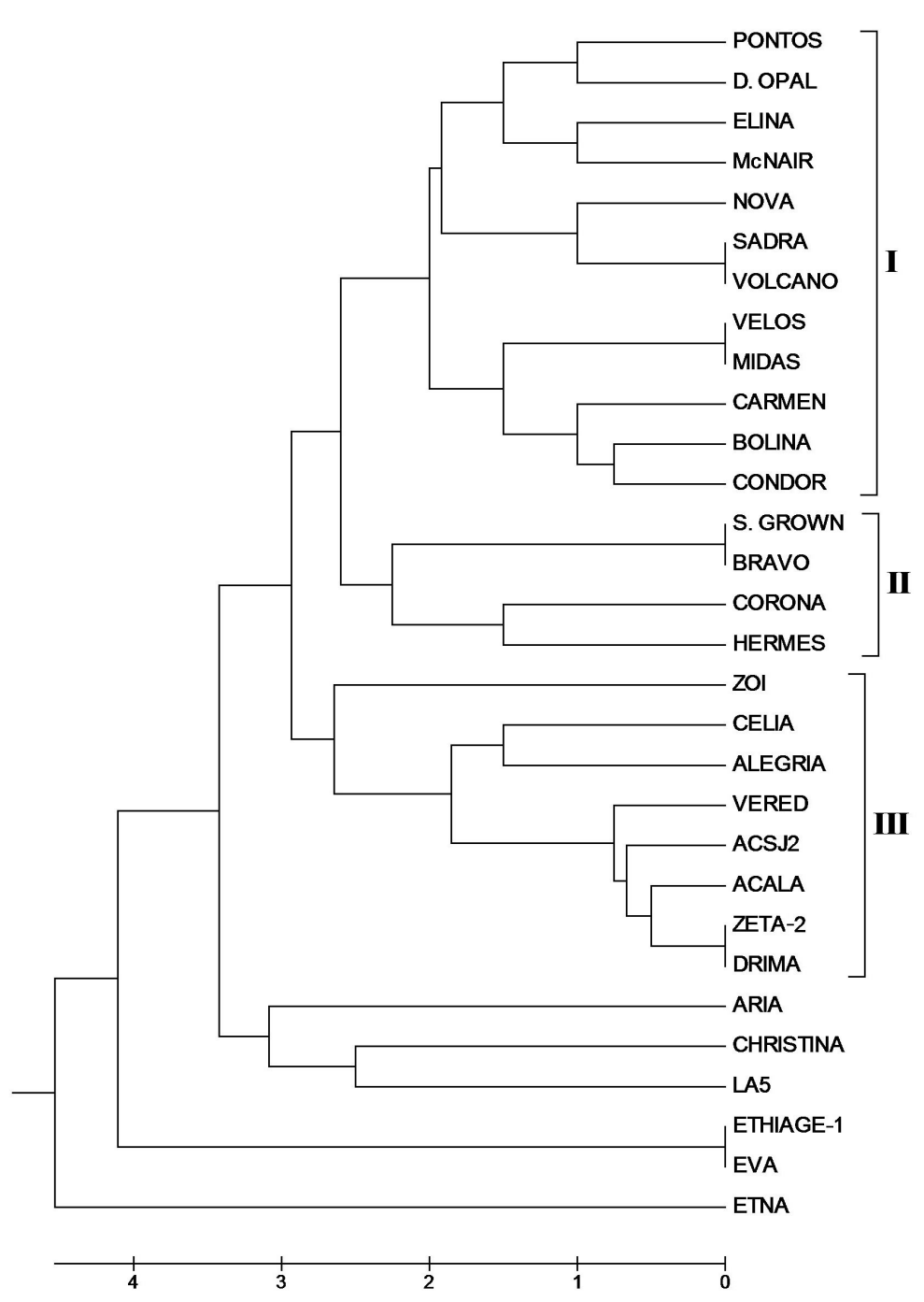

Figure 2. Dendrogram presenting the association of the 30 cotton cultivars determined by unweighted paired group method using arithmetic averages (UPGMA) cluster analysis of 17 polymorphic SSR marker loci.

The finding of genetic distance between the cotton cultivars using SSR molecular markers can be useful in marker-assisted selection (MAS). This acquires greater importance for cotton where the genetic base of improved cultivars is limited enough, because SSR molecular markers have higher analytical force, and hence, they reveal higher variation between genotypes compared to other molecular markers (Agrama and Tuinstra, 2003).

Each molecular marker was separately analyzed with the SPSS 15.0 statistical software in order to find out the correlation of each marker with the fiber agronomic traits as have been studied by the Cotton and Industrial Plants Institute (Experiments 2002-2003, Table 1). We found 6 molecular markers in total that show a correlation with one or more agronomic 
traits (Table 3). The BNL3408B-143 marker was found to be correlated $(\mathrm{P}=0.001)$ with micronaire. The correlation coefficient equals 0.70 , indicating a moderately strong relationship between micronaire and BNL3408B-143. Similar correlation between BNL3408, which is located on chromosome 3, and micronaire has been reported by Kantartzi and Stewart (Kantartzi and Stewart, 2008), who studied 56 lines of G. arboreum using 98 SSR molecular markers. In this study, they found 3 additional molecular markers correlated with micronaire. These molecular markers are located on chromosomes 3, 9 and 16. The SSR BNL1317 marker located on chromosome 9 is also correlated with micronaire. These findings suggest that chromosomes 3 and 9 contain loci affecting micronaire, since at least 2 molecular markers that correlate with micronaire are located on these chromosomes.

Table 3. The correlation between agronomic traits and SSR molecular markers for 30 cotton cultivars.

\begin{tabular}{|c|c|c|c|c|}
\hline Lint yield & $\begin{array}{l}\text { BNL1317A-184 } \\
\mathrm{r}=0.433^{*}\end{array}$ & $\begin{array}{l}\text { BNL3590A-193 } \\
\mathrm{r}=0.364^{*}\end{array}$ & & \\
\hline Fiber, $2.5 \%$ span length & $\begin{array}{l}\text { BNL3590-180 } \\
\mathrm{r}=0.42^{*}\end{array}$ & & & \\
\hline Lint percentage & $\begin{array}{l}\text { BNL1440A-230 } \\
r=0.465^{*}\end{array}$ & $\begin{array}{l}\text { BNL2634A-254 } \\
\mathrm{r}=0.487 * *\end{array}$ & $\begin{array}{l}\text { BNL1440A-234 } \\
\mathrm{r}=-0.465^{*}\end{array}$ & \\
\hline Fiber micronaire & $\begin{array}{l}\text { BNL1317B-198 } \\
\mathrm{r}=0.55^{* *}\end{array}$ & $\begin{array}{l}\text { BNL3408B-143 } \\
\mathrm{r}=0.7 * *\end{array}$ & $\begin{array}{l}\text { CM43A-102 } \\
\mathrm{r}=0.49^{* *}\end{array}$ & $\begin{array}{l}\text { CM43B-106 } \\
\mathrm{r}=0.51 * *\end{array}$ \\
\hline Fiber micronaire & $\begin{array}{l}1317 \mathrm{~B}-194 \\
\mathrm{r}=-0.39^{*}\end{array}$ & $\begin{array}{l}1317 \mathrm{~A}-188 \\
\mathrm{r}=-0.38^{*}\end{array}$ & $\begin{array}{l}\text { CM43A-106 } \\
\mathrm{r}=-0.49 * *\end{array}$ & $\begin{array}{l}\text { CM43B-118 } \\
\mathrm{r}=-0.51^{* *}\end{array}$ \\
\hline Fiber strength & $\begin{array}{l}\text { BNL1317A-180 } \\
\mathrm{r}=0.381 *\end{array}$ & $\begin{array}{l}\text { BNL3590A-185 } \\
\mathrm{r}=0.52 * *\end{array}$ & $\begin{array}{l}\text { BNL3590-180 } \\
\mathrm{r}=0.52 * *\end{array}$ & \\
\hline Fiber strength & $\begin{array}{l}\text { BNL3590B-186 } \\
r=-0.5^{*}\end{array}$ & $\begin{array}{l}\text { BNL1317A-184 } \\
\mathrm{r}=-0.379^{*}\end{array}$ & & \\
\hline
\end{tabular}

*Indicates significance at $\mathrm{P}=0.05 ; * *$ Indicates significance at $\mathrm{P}=0.01$.

Molecular markers BNL1317B-198, CM43A-102 and CM43A-106, which correlated with fiber length and micronaire, revealed a negative correlation between the 2 traits. BNL1317B-198 and CM43A-102, which correlated negatively with fiber length correlated positively with micronaire, while the reverse correlation was seen for CM43A-106. The above negative correlation suggests that higher fiber length values correspond with lower micronaire values and vice versa. A similar negative correlation has been reported by Kantartzi and Stewart (2008), who analyzed 56 cultivars of $G$. arboreum using 98 SSRs.

From the analysis of our results concerning the correlation of SSR of molecular markers with the agronomic traits of fiber, it is likely that the molecular markers showing correlations with the fiber characteristics are closely linked to genes that control the qualitative characteristics of fiber and affect its growth (Abdurakhmonov et al., 2007). SSR molecular markers could also prove to be useful in the understanding of the molecular base of fiber growth, while they could be used in parallel in various breeding programs and mainly in programs that are aimed at improving the quality of cotton fiber as well as increasing yield. Recent studies have found that the molecular markers that show a correlation with the qualitative characteristics of fiber are located almost in all chromosomes of cotton (Guo et al., 2003; Park et al., 2005; Zhang et al., 2005; Abdurakhmonov et al., 2007; Kantartzi and Stewart, 2008). Molecular markers for lint percentage have been found on chromosomes 5 , $9,10,12,16,18,23$, and 26 , for micronaire on chromosomes 3,9 and 16 , for fiber strength on chromosomes 12, 15, 17, and 18, and for fiber length on chromosomes 2, 18 and 26. 
Our results suggest that for an effective MAS we need to use a large number of SSRs that will cover the 26 chromosomes of the cotton genome in high density. The genetic variation identified by the SSR markers, if imported into the various breeding programs, will facilitate the incorporation of desirable QTL regions and removal of the undesirable regions from parental lines in a breeding program so as to achieve the optimal result (Liu and $\mathrm{Wu}, 1998$ ). The recessive nature of QTLs in regard to the qualitative characteristics of fiber (Kohel et al., 2001) renders MAS a desirable method for breeding programs aimed at the improvement of fiber. Moreover, the recessive nature of $G$. barbadense alleles that affect the qualitative characteristics of fiber, explains the difficulty in incorporating qualitative characteristics from $G$. barbadense cultivars to those of $G$. hirsutum. Finally, it is important to take into account the negative cross-correlation that exists between the qualitative traits of cotton fiber such as the one existing between micronaire and fiber length (Kantartzi and Stewart, 2008), in order to direct the breeding program towards the desirable character without downgrading another qualitative character.

\section{ACKNOWLEDGMENTS} (GSRT).

\section{REFERENCES}

Abdalla AM, Reddy OUK, El-Zik KM and Pepper AE (2001). Genetic diversity and relationships of diploid and tetraploid cottons revealed using AFLP. Theor. Appl. Genet. 102: 222-229.

Abdurakhmonov IY, Buriev ZT, Saha S, Pepper AE, et al. (2007). Microsatellite markers associated with lint percentage trait in cotton, Gossypium hirsutum. Euphytica 156: 141-156.

Agrama HA and Tuinstra MR (2003). Phylogenetic diversity and relationships among sorghum accessions using SSRs and RAPDs. Afr. J. Biotechnol. 2: 334-340.

Akkaya MS, Shoemaker R, Specht JE, Bhagwat AA, et al. (1995). Integration of simple sequence repeat DNA markers into a soybean linkage map. Crop Sci. 35: 1439-1445.

Anderson JA, Churchill GA, Autrique JE, Tanksley SD, et al. (1993). Optimizing parental selection for genetic linkage maps. Genome 36: 181-186.

Andersen JR and Lubberstedt T (2003). Functional markers in plants. Trends Plant Sci. 8: 554-560.

Bertini CHCM, Schuster I, Sediyama T, Barros EG, et al. (2006). Characterization and genetic diversity analysis of cotton cultivars using microsatellites. Genet. Mol. Biol. 29: 321-329.

Frelichowski JE Jr, Palmer MB, Main D, Tomkins JP, et al. (2006). Cotton genome mapping with new microsatellites from Acala 'Maxxa' BAC-ends. Mol. Genet. Genomics 275: 479-491.

Guo WZ, Zhang TZ, Shen XL, Yu JZ, et al. (2003). Development of SCAR marker linked to a major QTL for high fiber strength and its usage in molecular-marker assisted selection in upland cotton. Crop Sci. 43: 2252-2256.

Gutierrez OA, Basu S, Saha S, Jenkins JN, et al. (2002). Genetic distance among selected cotton genotypes and its relationship with $\mathrm{F}_{2}$ performance. Crop Sci. 42: 1841-1847.

Hakki EE, Savaskan C and Akkaya MS (2001). Genotyping of Anatolian doubled-haploid durum lines with SSR markers. Euphytica 122: 257-262.

Han Z, Wang C, Song X, Guo W, et al. (2006). Characteristics, development and mapping of Gossypium hirsutum derived EST-SSRs in allotetraploid cotton. Theor. Appl. Genet. 112: 430-439.

Iqbal MJ, Aziz N, Saeed NA, Zafar Y, et al. (1997). Genetic diversity evaluation of some elite cotton varieties by RAPD analysis. Theor. Appl. Genet. 94: 139-144.

Kantartzi SK and Stewart JM (2008). Association analysis of fibre traits in Gossypium arboreum accessions. Plant Breed. 127: 173-179.

Kohel RJ, Yu J, Park YH and Lazo GR (2001). Molecular mapping and characterization of traits controlling fiber quality 
in cotton. Euphytica 121: 163-172.

Li H, Luo J, Hemphill JK, Wang JT, et al. (2001). A rapid and high yielding DNA miniprep for cotton (Gossypium spp). Plant Mol. Biol. Rep. 19: 183a-183e.

Liu S, Saha S, Stelly D, Burr B, et al. (2000a). Chromosomal assignment of microsatellite loci in cotton. J. Hered. 91: 326-332.

Liu S, Cantrell RG, McCarty JC and Stewart JM (2000b). Simple sequence repeat-based assessment of genetic diversity in cotton race stock accessions. Crop Sci. 40: 1459-1469.

Liu XC and Wu JL (1998). SSR heterogenic patterns of parents for marking and predicting heterosis in rice breeding. Mol. Breed. 4: 263-268.

Lu J and Myers O (2002). Genetic relationships and discrimination of ten influential upland cotton varieties using RAPD markers. Theor. Appl. Genet. 105: 325-331.

Multani DS and Lyon BR (1995). Genetic fingerprinting of Australian cotton cultivars with RAPD markers. Genome 38: 1005-1008.

Nguyen TB, Giband M, Brottier P, Risterucci AM, et al. (2004). Wide coverage of the tetraploid cotton genome using newly developed microsatellite markers. Theor. Appl. Genet. 109: 167-175.

Park YH, Alabady MS, Ulloa M, Sickler B, et al. (2005). Genetic mapping of new cotton fiber loci using EST-derived microsatellites in an interspecific recombinant inbred line cotton population. Mol. Genet. Genomics 274: 428-441.

Rohlf FJ (2000). NTSYS-pc Numerical Taxonomy and Multivariate Analysis System. Version 2.1. Manual. Applied Biostatistics Inc., New York.

Rong J, Abbey C, Bowers JE, Brubaker CL, et al. (2004). A 3347-locus genetic recombination map of sequence-tagged sites reveals features of genome organization, transmission and evolution of cotton (Gossypium). Genetics 166: 389-417.

Saghai Maroof MA, Biyashev RM, Yang GP, Zhang Q, et al. (1994). Extraordinarily polymorphic microsatellite DNA in barley: species diversity, chromosomal locations, and population dynamics. Proc. Natl. Acad. Sci. U. S. A. 91: 5466-5470.

Sambrook J, Fritsch EF and Maniatis T (1989). Molecular Cloning: Laboratory Manual. Vol. 3. 2nd edn. Appendix C-1. Cold Spring Harbor, New York.

Tatineni V, Cantrell RG and Davis DD (1996). Genetic diversity in elite cotton germplasm determined by morphological characteristics and RAPDs. Crop Sci. 1996: 186-192.

Wendel JF, Brubaker CL and Percival AE (1992). Genetic diversity in Gossypium hirsutum and the origin of upland cotton. Am. J. Bot. 79: 1291-1310.

Zhang HB, Li Y, Wang B and Chee PW (2008). Recent advances in cotton genomics. Int. J. Plant Genomics 2008: 742304.

Zhang YX, Lin ZX, Li W, Tu LL, et al. (2007). Studies of new EST-SSRs derived from Gossypium barbadense. Chin. Sci. Bull. 52: 2522-2531.

Zhang ZS, Xiao YH, Luo M, Li XB, et al. (2005). Construction of a genetic linkage map and QTL analysis of fiber-related traits in upland cotton (Gossypium hirsutum L.). Euphytica 144: 91-99. 